\title{
Abwechslungsreicher Mix auf dem MTRA-Neujahrssymposium
}

Am Samstag, dem 29. Januar 2022 findet zum zweiten Mal das MTRA-Neujahrssymposium als digitale Veranstaltung statt. Nachdem in diesem Jahr 140 medizinischtechnische Radiologieassistentinnen und -assistenten an der Veranstaltung teilgenommen haben, wollen wir an den Erfolg anknüpfen: Unter der wissenschaftlichen Leitung von Frau Claudia Mundry ist wieder ein spannendes und abwechslungsreiches Programm entstanden.

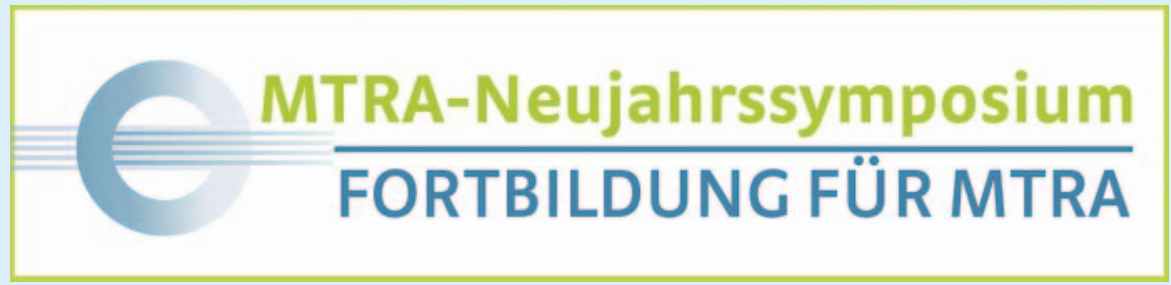

Das Fortbildungsprogramm startet mit der bunten Welt der Gefäße, in der unter anderem die Bildgebungsmöglichkeiten MRT, CT und DSA besprochen werden.
In der zweiten Sitzung werden 10 Schritte zur erfolgreichen Kardio-CT präsentiert und Fälle der MRT-Notfalldiagnostik vorgestellt. 
Im zweiten Teil des MTRA-Neujahrssymposiums erwartet die Teilnehmerinnen und Teilnehmer ein radiologischer Mix, bestehend aus Röntgen in 3-D, einem störungsfreien ECMOEinsatz und einem spannenden und kritisch beleuchteten Nachhaltigkeitsvortrag: „Die Plastikfreie Radiologie - ein (Alp)Traum“.
Der letzte Block der Veranstaltung widmet sich der mentalen Stärke im MTRA-Alltag.

Wir freuen uns auf zahlreiche Teilnehmende und ein spannendes digitales MTRA-Neujahrssymposium 2022!
Seien Sie also dabei: Das ausführliche Programm und Informationen zur Anmeldung finden Sie unter:

www.vmtb.de > Veranstaltungskalender 